\title{
Narrativas de crianças sobre a escola: desafios das análises
}

\author{
Maria da Conceição Passeggi, Gilcilene \\ Nascimento \& Senadaht Rodrigues
}

\begin{abstract}
Resumo
O objetivo do texto é discutir procedimentos de análise de narrativas de crianças, de 6 a 12 anos de idade, sobre suas experiências em escolas na zona rural, na periferia urbana e em classes hospitalares, no Nordeste brasileiro. As pesquisas nesses três contextos integram projetos mais amplos, financiados pelo CNPq-Brasil, e se propõem a investigar os sentidos construídos, narrativamente, pelas crianças sobre a escola. Inicialmente, situaremos, as narrativas autobiográficas como método da pesquisa qualitativa em educação, na interface da pesquisa (auto)biográfica e da Psicologia cultural. Em seguida, apresentamos uma breve descrição do protocolo comum utilizado e discutiremos os desafios encontrados na constituição do corpus e nas opções de análise. Os achados da pesquisa revelam a incidência do contexto sociocultural sobre os modos de experienciar o mundo escolar, desmitificando, por vezes, a oposição entre o rural e urbano, demostrando a força da violência das periferias urbanas sobre a escola, mas perspectivando também a escola como símbolo de refúgio e de retorno à vida. Do ponto de vista teórico, a análise evidencia os desafios exigidos para preservar a visão de mundo das crianças, corrobora as potencialidades heurísticas e hermenêuticas de suas narrativas e indica aproximações significativas para a análise da palavra da criança para a pesquisa qualitativa em Educação.
\end{abstract}

Palavras-chave:

narrativas; crianças; análise; pesquisa qualitativa. 


\title{
Children's narratives about school: challenges of analysis
}

\begin{abstract}
The purpose of the text is to discuss procedures for the analysis of children's narratives, from 6 to 12 years old, about their experiences in rural schools, urban periphery and hospital classes in the Brazilian Northeast. Researches in these three contexts is part of broader projects, funded by CNPq-Brasil (Brazilian Council for Scientific and Technological Development), and aims to investigate the constructed senses, narratively by children about school. Initially, autobiographical narratives are situated as a method of qualitative research in education, at the interface of (auto) biographical research and cultural psychology. Then, after a brief description of the common protocol used, is put into question the challenges encountered both in the constitution of the corpus and in the analysis options. The research findings reveal the incidence of the socio-cultural context on the ways of experiencing the school world, sometimes demystifying the opposition between rural and urban, reinforcing the violence of the peripheries over school, but also looking at school as a symbol of refuge and return to life. From the theoretical point of view, the analysis highlights the challenges required to preserve the world view of children, corroborates the heuristic and hermeneutical potentialities of their narratives and indicates significant approaches for the analysis of the child's word for qualitative research in Education.
\end{abstract}

Keywords: narratives; children; analyze; qualitative research.

\section{Récits d'enfants sur l'école: questions d'analyse et d'interprétation}

Résumé: L'objectif du texte est de discuter des procédures pour l'analyse des récits d'enfants, âgés de 6 à 12 ans, sur leurs expériences à l'école, dans la zone rurale, dans la périphérie urbaine et dans les classes à l'hôpital, dans le Nord-Est du Brésil. Les recherches dans ces trois contextes font partie de projets plus larges, financé par le CNPqBrésil, qui vise à étudier les sens que les enfants attribuent à l'école dans leurs récits. Dans un premier temps, nous présentons les récits autobiographiques comme méthode de recherche qualitative, en situant nos études à la croisée de la recherche (auto) biographique en éducation et de la psychologie culturelle. Ensuite, nousdonnons une brève description du protocole commun utilisé e nous discuterons des défis rencontrés dans la constitution du corpus et dans les options d'analyse. Les résultats de la recherche révèlent l'incidence du contexte socioculturel sur les façons de concevoir les expériences dans le monde scolaire, démystifiant, parfois, l'opposition entre le rural et l'urbain, en identifiant la force de la violence des périphéries urbaines sur l'école, mais symbolisant l'école, également, comme refuge et retour à la vie. Du point de vue théorique, l'analyse met en évidence les défis pour préserver la vision du monde des enfants, corrobore les potentialités heuristiques et herméneutiques de leurs récits et signale des approches significatives pour l'analyse de la parole de l'enfant pour la recherche qualitative en éducation.

Mots clés: récits; enfants; analyse; recherche qualitative.

\section{Narrativa de niños acerca de la escuela: cuestiones del análisis e interpretación}

Resumen: El objetivo del texto es discutir procedimientos de análisis de narrativas de niños y niñas, de 6 a 12 años de edad, sobre sus experiencias en escuelas de la zona rural, de la periferia urbana y en clases hospitalarias, en el Nordeste brasileño. Las investigaciones en esos tres contextos integran proyectos más amplios, financiado por el CNPq-Brasil, que se propone a investigar los sentidos construidos, narrativamente, por los niños sobre la escuela. Inicialmente, situaremos, las narrativas autobiográficas como método de investigación cualitativa, situando-nos en la perspectiva de la investigación (auto) biográfica en educación y de la Psicología cultural. Presentamos una breve descripción del protocolo común utilizados y discutiremos los desafíos encontrados en la constitución del corpus, como en las opciones de análisis. Los hallazgos de la investigación revelan la incidencia del contexto sociocultural sobre los modos de vivir experiencias en el mundo escolar, desmitificando a veces la oposición entre lo rural y lo urbano, evidenciando la fuerza de la violencia de las periferias sobre la escuela, pero mirando también la escuela como símbolo de refugio y de retorno a la vida. Desde el punto de vista teórico, el análisis evidencia los desafíos exigidos para preservar la visión del mundo de los niños, corrobora las potencialidades heurísticas y hermenéuticas de sus narrativas e indica aproximaciones significativas para el análisis de la palabra del niño para la investigación cualitativa en educación.

Palabras clave: relatos; niños; análisis; investigación cualitativa. 


\title{
À guisa de introdução: "traduzir sem trair"
}

\begin{abstract}
Transmitir ao leitor os meios para lançar sobre as declarações que vai ler esse olhar que dá razão [e] o mesmo acolhimento fervoroso que certa tradição de leitura reserva às formas mais altas da poesia ou da filosofia.
\end{abstract}

(Bourdieu, 2003, p. 712)

Escolhemos para esta reflexão pesquisas com narrativas de crianças sobre suas experiências escolares, vividas em três situações escolares: no campo, na periferia urbana e na transição entre a classe hospitalar e a escola regular. As pesquisas integram projetos financiados pelo CNPq-Brasil, cujo objetivo é investigar os sentidos construídos, narrativamente, por crianças de 6 a 12 anos de idade, sobre o tempo vivido na escola, a organização e espaço escolar.

As palavras de Bourdieu, na epígrafe, sintetizam a postura que adotamos em nossas pesquisas com narrativas autorreferenciais, pois entendemos que o grande desafio é encontrar ao longo do processo investigativo e de escrita, modos adequados para "traduzir sem trair" o que nos confiaram os participantes: sentimentos, medos, desejos, alegrias, irreverências, hesitações, incertezas... Como fazer para que essas narrativas pessoais despertem em que lê o respeito reservado às palavras do pesquisador?

Essa é a ideia central que perpassa a reflexão sobre procedimentos que utilizamos na constituição do corpus, análises, interpretação e escrita, visando a uma "democratização da postura hermenêutica". (Bourdieu, 2003, p. 712). Com efeito, quando se trata da pesquisa com crianças, e não sobre elas, o desafio é duplo: por um lado, superar o preconceito contra a produção do conhecimento com base em percepções subjetivas, por outro lado, legitimar a palavra e a reflexão da criança sobre suas próprias experiências. O primeiro desafio concerne a rupturas epistemológicas, em jogo na pesquisa qualitativa; o segundo diz respeito às rupturas com o saber do senso comum e suas repercussões sobre uma visão adultocêntrica em ciência, que se recusa a conceber a criança pelo que ela "já compreende", e não pelo que ela "ainda não entende". O que exige do pesquisador muito rigor para interpretar a interpretação da criança no seu esforço de dar sentido aos acontecimentos. Muitas vezes, a criança percebe apenas com o corpo o que lhe acontece, e não quer, ou não deseja verbalizar. O cuidado é, portanto, evitar reduzir seus modos de refletir e de interpretar o mundo.

Inicialmente, discutiremos o interesse pelas narrativas de si como fonte e método de pesquisa qualitativa em Educação. Apresentamos, em seguida, procedimentos utilizados para a construção do corpus e, finalmente, discutimos as escolhas para as 
análises e estudo dos sentidos atribuídos à escola pelas crianças em suas narrativas. Em conclusão, sinalizamos as potencialidades heurísticas e hermenêuticas da palavra da criança, como sujeito de direitos, histórico, narrador e autor de suas histórias, finalizando sobre a importância das fontes autorreferenciais para a compreensão do humano, desde tenra idade, e aproximações sugestivas para pesquisa qualitativa.

\section{Narrar para compreender. Compreender-se para resistir}

As narrativas de si tornaram-se, nos últimos trinta anos, uma fonte privilegiada da pesquisa qualitativa. Essa "virada narrativa" deve-se, em parte, à "descoberta" de que o humano, como afirma Ricœur (2010), se compreende e se interpreta ao narrar. Nessas narrativas de si, autorreferenciais ou autobiográficas, a pessoa que narra, ao se tomar como objeto de reflexão, desdobra-se em personagem, narrador e autor da narrativa. É na narração que se alternam essas diferentes versões de si: o eu que viveu ou viverá a história, o eu que narra, o eu que se considera o autor do texto. Para entender a distinção entre autor e narrador, podemos dizer que o narrador é um ser de linguagem, que se constitui na própria ação de narrar. Sem narração não existe narrador. Ele nasce com a narrativa, vive nela e morre com ela. Já o autor é o ser empírico, de carne e osso, que viveu antes e viverá depois da narrativa. Pois o autor pode, a cada vez, assumir o papel de narrador para reinterpretar os mesmos acontecimentos e 'inventar' novas versões da história e de si mesmo como narrador, autor e personagem.

Se intuitivamente compreendemos o que é uma narrativa, por que é tão difícil conceituá-la? "Inumeráveis são as narrativas do mundo", nos diz Roland Barthes (1966, p.01). Entre elas, encontramos as narrativas históricas, literárias, jurídicas, bíblicas, folclóricas, midiáticas, digitais, ideográficas, fílmicas etc. Para esse autor, "a narrativa começa com a própria história da humanidade" e é por volta dos três anos de idade que a criança 'inventa', ao mesmo tempo, "a frase, a narrativa e o Édipo" (Barthes, 1966, p.27). Poderíamos então admitir que o processo de humanização, tanto do ponto de vista filogenético, quanto ontogenético, se confunde com essa aptidão humana para narrar. Sem entrar em controvérsias, essa constatação se evidencia quando uma patologia neurológica, como o mal de Alzheimer ou a síndrome de Korsakoff, ou ainda uma situação traumática, por exemplo, subtrai essa aptidão para narrar, seja verbalmente, com gestos, ou com outros instrumentos semióticos.

Arriscamo-nos a definir, brevemente, a narrativa como uma síntese provisória do que aconteceu, para dar sentido ao acontecimento e ao que nos acontece, independentemente, dos instrumentos semióticos utilizados por quem narra. 


\section{Narrativas de si na infância: como recolher fontes autobiográficas?}

A pesquisa (auto) biográfica, preocupada com os processos de subjetivação e de socialização, escolhe, entre as inúmeras narrativas do mundo, as narrativas de si, como lugar fundante do ser e do devir humano (Delory-Momberger, 2005). Se para Bruner (2014, p.75), "a criação do eu é uma arte narrativa", por que não observar como se dá essa criação desde a infância? Que paisagens internas e externas são tematizadas pela criança? Que sentidos ela Ihes dá? É a partir dos trabalhos precursores de Bruner (1997), que o interesse pelas narrativas da criança emerge na Psicologia cultural como objeto de investigação qualitativa (Passeggi, Nascimento \& Oliveira, 2016; Passeggi, 2014; Passeggi, 2016). Para Bruner (1997), a criança aprende a utilizar a linguagem e a elaborar narrativas, por volta dos três anos de idade, não para resolver "dramas pessoais", mas para entender o que the acontece face ao que está acontecendo em seu redor.

Com base nos estudos de Delory-Momberger (2008), recorremos a três conceitos relativos às operações mentais, verbais e comportamentais pelas quais uma pessoa se inscreve temporalmente na narrativa de si: "biografização", "heterobiografização" e "autobiografização". A criança ingressa na cultura, primordialmente, pelas histórias que the são contadas, ou seja, pelo processo de heterobiografização, quando se representada, mentalmente, nas histórias que Ihes são contadas. Mas, se representa também ao contar a sua própria história, autobiografização, e ao contar a história de alguém, biografização.

Nesse sentido, as operações de auto, hétero, biografização não seriam apenas modos de representação do mundo, mas de construção da realidade e da própria subjetividade. Para Bakhtin (1985, p.118), a expressão narrativa "exerce um efeito reversivo sobre a atividade mental: ela põe-se a estruturar a vida interior, a dar-Ihe uma expressão ainda mais definida e mais estável". De modo que ela não se limitaria a um conjunto de sequências linguísticas, abstratas, desenraizadas do corpo e das emoções. Como afirma Bronckart (1999, p.62), em Psicologia da linguagem, é mediante o esforço de interpretação "dos discursos narrativos que o funcionamento psíquico humano se expande, se enriquece e se reestrutura perpetuamente".

Esses princípios nos permitiram justificar a metodologia utilizada na recolha de narrativas de crianças em rodas de conversa, constituídas por grupos de no máximo cinco crianças. O mais importante nessa escolha é a adoção de uma perspectiva dialógica entre as crianças e o pesquisador. As rodas de conversa foram realizadas com 34 crianças, na escola do campo; com 14 crianças, na escola da periferia urbana e com 03 crianças com doenças crônicas numa classe hospitalar. 
O protocolo (Lani-Bayle \& Passeggi, 2014; Passeggi et al. 2016) foi concebido, observando-se características próprias da cultura infantil: ludicidade, imaginário, interatividade e reiteração, como sugere Sarmento e Pinto (2004). Ele prevê uma situação de "faz de conta" com a "presença" de um pequeno alienígena, chamado Alien, vindo de um planeta que não tinha escolas ou hospitais. A ideia era provocar um distanciamento espontâneo para despertar a imaginação, a reflexão, e possibilitar à criança lidar com eventuais conflitos na roda de conversa. As crianças podiam entrar e sair da roda quando quisessem.

O diálogo se estruturava em torno de três momentos: abertura (apresentação do Alien às crianças); conversa entre os participantes; e fechamento (retorno do Alien ao seu planeta). Com as crianças da classe hospitalar, consideramos como roda de conversa, o diálogo entre cada uma delas, a pesquisadora e o Alien.

As rodas foram gravadas em vídeo nas escolas do campo e da periferia e áudio com as crianças hospitalizadas, com prévio consentimento dos responsáveis e o assentimento das crianças, respeitando os cuidados éticos de riscos e benefícios para os participantes da pesquisa.

\section{A constituição do corpus: a opção por narrativas coletivas}

A leitura das transcrições das rodas de conversa revelou como característica fundante da interação, que as crianças contavam suas experiências com frases curtas, fortemente sintéticas e densas de sentido. Surgiu daí a primeira dificuldade teórica para a constituição do corpus e as análises. Tornou-se imperativo romper com os padrões canônicos da narrativa, contada por um único narrador, segundo um modelo constituído por peripécias, com começo, meio e fim. Observamos que os pequenos fragmentos de suas falas iam se encadeando no fio da conversa e terminavam por constituir sequências narrativas, construídas coletivamente. A fala de uma criança ia complementando o que dizia a outra. Tínhamos então um ganho teórico-metodológico, que nos permitiu considerar essas sequências como narrativas coletivas, polifônicas, harmonicamente constituídas pelas múltiplas vozes que delas participavam.

Para Barthes (1966), uma frase, afirmativa ou negativa, pode ser considerada como esboço de uma pequena narrativa. Somamos a essa ideia a concepção minimalista de narrativa de vida, sugerida por Bertaux (2010). Para Bertaux, existe narrativa de vida desde que haja descrição, sob uma forma narrativa, de um fragmento da experiência vivida. O corpus para a análise está, portanto, constituído por micronarrativas. Observa-se que na medida em que a conversa avança, as crianças vão construindo coletivamente o sentido para o que lhes acontece na escola. Conforme o exemplo seguinte, elas vão encadeando suas respostas para responder à pergunta da pesquisadora: Vocês já pararam para pensar como seria a vida sem escola? 
Cláudia - Nunca!

Kelly - Seria muito ruim. A pessoa não aprenderia a ler, estudar.

Gaspar - E assim, se não fosse para a escola, a gente não ia arrumar um trabalho também.

No processo de constituição do corpus para a análise, textualizamos esses fragmentos como uma sequência narrativa, retirando os nomes fictícios das crianças, o que gerou a seguinte sequência: "Nunca! Seria muito ruim. A pessoa não aprenderia a ler, estudar. E assim, se não fosse para a escola, a gente não ia arrumar um trabalho também". Esse ganho metodológico tem demonstrado que essa opção permite analisar, com base numa narrativa coletiva, o sentido que as crianças vão atribuindo às suas experiências escolares, conjuntamente.

Procuramos ainda, na constituição do corpus, observar princípios éticos na transposição da oralidade para a escrita, para reduzir, na publicação dos excertos as marcas da oralidade, de modo que permitisse melhor "falar à sensibilidade, sem sacrificar ao gosto do sensacional” (Bourdieu, 2003, p. 711). As operações envolvidas nesse processo de textualização fazem do pesquisador um mediador entre os narradores e quem os lê. Daí a responsabilidade de quem escreve para criar condições necessárias à compreensão e à interpretação do que percebeu nas vozes, olhares, movimentos das crianças no momento da construção das narrativas.

\section{O que tematizam as crianças em suas narrativas?}

Adotamos a opção da análise temática, tal como ela é proposta por Poirier, Clapier-Vallandon e Raybaut (1996). Segundo os autores, foi a psicocrítica literária que restabeleceu o direito de cidadania à análise temática, que se opunha aos cânones da análise quantitativa nas Ciências Humanas. Para esses autores (1996, p. 215, tradução nossa), "no sentido clássico, o tema é uma categoria semântica, objeto do discurso. A análise temática procura metodicamente as unidades de sentido com base no que é dito pelo narrador, com relação aos temas".

Seguindo esse propósito, encontramos em Jovchelovitch e Bauer (2014) a inspiração para sistematizar os temas e as unidades de sentido. Para os autores, essa busca dos temas e unidades de sentido obedece a uma dupla redução, ou adensamento do texto original. Em primeiro lugar, recorremos a paráfrases para sintetizar o sentido do texto original. Por sua vez, essas sentenças são condensadas mediante palavras-chave. Esse adensamento do texto original se realiza por generalização e condensação de sentido. No quadro abaixo, exemplificamos esses procedimentos. 
Quadro 1. Procedimento gradual de adensamento das narrativas

\begin{tabular}{|c|c|c|}
\hline Transcrição literal da narrativa & $\begin{array}{c}\text { Paráfrases } \\
\text { Sentenças sintéticas }\end{array}$ & $\begin{array}{c}\text { Palavras-chave } \\
\text { Unidades de sentido }\end{array}$ \\
\hline $\begin{array}{l}\text { Um menino do } 4^{\circ} \text { ano foi ao } \\
\text { banheiro e arranjou uma briga lá. } \\
\text { Deu um bofete no olho do menino, } \\
\text { e o menino caiu, ficou lá. Ele era do } \\
1^{\circ} \text { ano. } \\
{[\ldots]} \\
\text { Para começo de história, as } \\
\text { meninas vieram me falar que Helena } \\
\text { tinha dito que iria me bater e eu, } \\
\text { como sou fraca, comecei a chorar. }\end{array}$ & $\begin{array}{l}\text { Agressões física e verbal } \\
\text { como signos de violência e } \\
\text { de poder dos mais velhos } \\
\text { e "fortes" contra os mais } \\
\text { jovens e "fracos". }\end{array}$ & $\begin{array}{l}\text { Brigas. Ameaças. } \\
\text { Agressões físicas. }\end{array}$ \\
\hline Tema: A violência na escola & & \\
\hline
\end{tabular}

Fonte: Banco de dados do GRIFARS-UFRN-CNPq, 2016.

No quadro acima, colocamos na coluna à esquerda, a transcrição de cada roda de conversa, na íntegra. Na coluna do meio, as sentenças que sintetizavam parágrafos da narrativa. Na coluna à direita, as unidades de sentido. Para identificar os temas recorrentes, passamos a colorir com cores diferentes os temas identificados, na medida em íamos realizando as leituras do texto integral. Os procedimentos de coloração e de adensamento da narrativa já constituem operações interpretativas do processo de análise. Para Jovchelovitch e Bauer (2014, p. 107), "o produto final constitui uma interpretação das entrevistas, juntando estruturas de relevância dos informantes com as do entrevistador. A fusão dos horizontes dos pesquisadores e dos informantes é algo que tem a ver com a hermenêutica".

\section{Os sentidos da escola: narrativas de si e estrutura social}

Apontamos agora alguns resultados advindos das análises. De maneira geral, observamos que os temas em torno do qual giram as rodas de conversa evidenciam o quanto os espaços escolares estão impregnados das especificidades contextuais que lhes dão contornos peculiares e influenciam a produção das narrativas sobre as experiências vividas e a constituição das crianças como pessoas que habitam esses contextos.

Os assuntos tematizados pelas crianças da escola do campo, por exemplo, estão estreitamente relacionados às estruturas socioculturais do contexto em que agem e interagem com o outro e com o mundo. A análise das rodas de conversa permite destacar, aqui, três temas centrais: O cotidiano na zona rural; Horizontes de expectativas propiciados pela escola; Ausência de horizontes num mundo sem escola. 
Com relação ao tema O cotidiano na zona rural, ele sintetiza as experiências vinculadas à realização diária de tarefas domésticas e agrícolas, evidenciando atividades típicas do contexto rural: plantar, cuidar dos animais, fazer cerca, providenciar lenha. O sentido que atribuem a essas atividades está, no entanto, mais próximo de uma colaboração familiar, de um tempo de aprendizagens intergeracional e cultural, do que de uma obrigação: "Ajudo quando quero". Carlos, Eduardo (7 anos) e Robson (6 anos) contam a seguinte narrativa coletiva para o Alien: "Ajudo mãe a arrumar a casa. Eu ajudo também! Eu trabalho fazendo cerca, limpando mato, plantando. Eu ajudo a plantar também".

Peloso (2015) destaca que as adversidades enfrentadas na condição de agricultoras não apagam a ludicidade própria de sua condição de criança. Cláudia, Kely e Gaspar (7 anos) veem de forma positiva a possibilidade de viver em comunidade. "Vamos jogar bola no campo. Pegar piaba! Ando de bicicleta. Ajudo a mãe. Leio um livro, faço as atividades de casa".

O segundo tema, Horizontes de expectativa propiciados pela escola, reproduz a concepção de escola como lugar de promessa de um futuro melhor, o que lhes possibilitaria realizar projetos de vida alternativos ao incerto e difícil futuro na roça. Estudar é, portanto, a alternativa mais assertiva para sair das condições precárias da zona rural. Assim, o sentido da escola está vinculado mais ao futuro do que ao presente, ela seria uma passarela para um futuro prometido, quando poderão, finalmente, ser "alguém na vida".

As crianças não surpreendem, quando explicitam para o Alien que a "função da escola" é potencializar a mobilidade social. Esse tema é abordado por crianças entre 8 e 11 anos de idade, que começam a vislumbrar horizontes profissionais. Wigna, Lilian Vera, Lulu, Kauã, Henry (11 anos) e Rafa (8 anos) explicam por que vêm à escola:

Para estudar! Para aprender a ler! Para quando ficar grande, arranjar um emprego! Para ser um doutor! Para ser um professor! Conseguir entrar na faculdade e ter um futuro melhor! Para ser alguém na vida. Para conseguir um futuro melhor. Trabalhar. Depender de nós mesmos. Para quando a gente ficar maior, a gente aprender as coisas. Ganhar bolsa. Fazer faculdade. Se formar.

Observamos que para essas crianças, incluindo as que moram em lugares mais distantes, em uma comunidade de remanescentes quilombolas, a escolarização abre-Ihes como horizonte o ingresso na universidade. O que sugere a interconexão entre o mundo rural e o mundo urbano, desmistificando percepções mais arcaicas de completa oposição. No processo de autobiografização, as crianças integram, por exemplo, narrativas ouvidas sobre o ensino superior: "Ganhar bolsa. Fazer faculdade. Se 
formar". Ao narrar seus projetos de vida, elas vão se constituindo como sujeitos reflexivos, suscetíveis de caminhar para sua emancipação: "Trabalhar. Depender de nós mesmos".

A terceira construção temática, Ausência de horizontes num mundo sem escola, reforça a importância da escola para os que vivem no campo. Para Gaspar (7 anos) e Raul (9 anos) só Ihes restaria o trabalho pesado na roça. Sem escolas, "Teria que trabalhar na roça! Se não existisse escola, estaria na roça, metendo a foice pra cima". O sentido que atribuem ao trabalho no campo e às tarefas domésticas é o de ajuda e colaboração à família. Se essa ajuda se justifica na infância, ela não poderia permanecer na vida adulta: "Seria horrível" um mundo sem escolas, pois o sentido da escola é assegurar melhores condições de vida no futuro.

No contexto da escola urbana, destacam-se como tema central das narrativas os diferentes modos de violência que vivenciam na escola e como se inserem na comunidade onde moram. Os conflitos e situações de agressões emergem como alertas para o Alien:

Aqui, um dia, teve uma guerra. Lá perto da minha casa. De frente, assim, minha tia morava. Lá perto da igreja. Parecia uma guerra. Um bocado de policial contra um bocado de ladrão. Tinha até um helicóptero [...] um tiroteio. Uma mulher levou um tiro na barriga. Nos peitos e na barriga.

Essa sequência narrativa foi construída por várias crianças. Na construção de narrativas como essa, observamos que elas eram entrecortadas por comportamentos contraditórios: risos, medo, silêncios, gestos e brincadeiras agressivas, que de certa forma sinalizavam um processo mais de naturalização do que de estranhamento, tendendo a beirar a banalização da violência.

O que conta Max (8 anos) para o Alien é representativo de brigas e agressões entre as crianças na escola, revelando, desde cedo, que para elas a relação entre agressor e vítima se estabelece como algo corriqueiro na escola. "Um menino do $4^{\circ}$. ano foi no banheiro e arranjou uma briga lá. Deu um bofete no olho do menino do $1^{\circ}$ ano. Ele caiu e ficou lá". O que causa estranhamento a Max, por exemplo, é que a criança menor "ficou lá", supostamente, sem reação e sem socorro. As ações na narrativa se sucedem como parte de um encadeamento "lógico", que já faz parte da trama da história. Os motivos das brigas são variados, imprevisíveis, ou injustificáveis, de pouca importância e talvez, por isso mesmo, desaparecem do enredo. Esse tipo de agressão acontece geralmente nos intervalos, na quadra, no banheiro, no pátio, como espaços liberadores de incivilidades.

Mesmo sendo recorrente, em suas narrativas, o fato de conviverem diariamente com a violência, seja ela física ou simbólica, as crianças apontam caminhos para uma 
escola diferente. Na sua mensagem de despedida, Rita (11 anos) diz ao Alien que a escola em seu planeta "tem que ter muitos amigos e muitas crianças para brincar. Não pode ter briga. E na sua rua, não pode ter bala, nem bandido". Na escola desejada, as crianças projetam uma cultura de paz, que se opõe à cultura de violência em sua comunidade, e a escola padece dentro dela o problema da violência existente fora da escola.

As análises das micronarrativas de crianças gravemente enfermas, que transitam entre a classe hospitalar e a escola regular, propõem questões temáticas: $E$ quando a primeira escola é no hospital?; E quando as rupturas são um (re)começo?; E quando retornar é permanecer na escola?.

A primeira temática está relacionada à narrativa de Rita (5 anos) que iniciou o processo de escolarização na classe hospitalar. Para Rita, o sentido da escola é de um lugar de alegria durante o tratamento de saúde. "Ela (a salinha da classe hospitalar) é grande. Eu acho bom. Acho muito bom. [...] Eu estudo aqui e eu gosto daqui". Para ela, o sentido da escola regular é o de lugar de socialização, da brincadeira, induzindo outra maneira de ser e de estar no mundo: "Tenho grandes amigos lá (na escola regular). Eu gosto de pular corda. Brincar de pega-pega. Brinco de esconde-esconde, de tica-tica. Eu estudo. Faço o nome e vou para casa. É assim [...]. Estudar! Estudar! Tem que aprender a fazer o nome!" Para uma criança fragilizada pelo adoecimento e que permaneceu enclausurada no hospital, a escola regular surge em sua narrativa, simbolicamente, como um retorno à normalidade da vida. Entre o brincar e fazer amigos, Rita narra seu processo de enculturação no universo escolar mediante a observação de suas normas e obrigações: "Tem que aprender a fazer o nome".

O segundo tema, E quando as rupturas são um (re)começo?, surge na narrativa de Maria (6 anos), que conta suas experiências entre o retorno à escola regular e um novo rompimento decorrente de recidivas de uma doença grave. Esse retorno é marcado pelo desafio de "ser diferente". Quando a pesquisadora lhe pede para dizer se é fácil fazer amigos em sua escola, ela lhe diz: "Mais ou menos. Só não, quando a gente vai de máscara". "Conte-nos mais sobre isso", pede a pesquisadora. Em resposta, vem o silêncio. Em seguida: "Eu já não lembro mais", diz Maria. Exposta a situações desagradáveis, do ponto de vista físico, dores, mal-estar, palidez, perda de peso, de cabelo, essas condições de vida, no limiar do insustentável, tendem a repercutir sobre a vida emocional: medo, ansiedade, suscetibilidade, depressão, sensação de abandono.

O sentido de ir de máscara à escola é se destacar dos outros como um ser diferente. E nesse caso, nem sempre é fácil fazer amigos. O silêncio, que antecede à frase "Eu já não lembro mais", pode simbolizar, seja a impossibilidade de narrar, como acontece em situações pós-traumáticas, seja uma tática de resiliência subjacente ao desejo de esquecer algo que traz sofrimentos no presente e sinalizar nova ruptura com a escola, no futuro. 
O terceiro tema, E quando retornar é permanecer na escola?, surge na narrativa de Amanda (6 anos), que transita entre a escola regular e a classe hospitalar. Para ela, o sentido da escola é um lugar de desafios, de superação, de construção e manutenção de elos. Ela conta para o Alien que tem muitos amigos na escola (regular): "Alan, Ariele, Polyana, Laurinha, Jennifer, e, deixa-me ver mais quem: Laís, também Arthur, João Lucas, Eric e Brendo. Dez. E eles são muito legais". De modo que o Alien só pode ser amigo de seus muitos amigos se ele souber "se divertir. Fazer amizade e conversar muito". A sua máxima é: "Caladinho não faz amiguinho!" A interação com o outro é o que permite (re)significar, assertivamente, seus vínculos de amizade no retorno à escola, marcado por problemas de timidez e retraimento. O entendimento de que para fazer amigos na escola é preciso vencer a timidez, "Caladinho não faz amiguinho", revela o seu processo de reflexão na construção de sua subjetividade como um ser ativo, decidido a adotar uma postura de enfrentamento e superação.

\section{Conclusões em aberto}

As reflexões acima evidenciam como eixo comum a importância e o papel que a escola desempenha na vida das crianças nos diferentes contextos estudados. Suas narrativas sinalizam que em suas experiências cotidianas, dentro e fora da escola, se refletem estruturas socioculturais que incidem na construção de seus pontos de vista sobre o sentido da escola em suas vidas e sobre elas mesmas em seus projetos de ser e de estar no mundo. Para as crianças da escola do campo, o seu horizonte de expectativas está fortemente vinculado às aprendizagens escolares. Para as crianças que vivem na periferia urbana, suas narrativas revelam o anseio pela paz subsumida pela violência que adentra a escola, naturalizando e banalizando conflitos e comportamentos agressivos, provocadores de questionamentos permanentes sobre amizade, tolerância, cooperação, paz, tranquilidade, segurança, medo, abandono. Para as crianças que transitam entre a escola regular e a classe hospitalar, os processos de iniciação ou de continuidade da escolarização na escola regular, representam, essencialmente, o retorno à normalidade da vida.

Os resultados apresentados são apenas exemplos de como estamos realizando uma escrita interpretativa de narrativas de crianças, intentando refletir sobre os sentidos de "riscos e benefícios" da escola para a construção da realidade e de si mesmas como sujeitos atravessados por narrativas que escutam em instâncias socioculturais e que agem sobre elas e sua visão de mundo. Certamente, cada pesquisa aqui apresentada traz resultados muito mais abrangentes, pois respondem a objetivos específicos de cada investigação, com maior clareza e pertinência.

Interessa-nos, prioritariamente, lembrar que nosso propósito foi o de apresentar os procedimentos que adotamos para a constituição do corpus e as decisões que se 
tornaram imperativas para as análises. Os procedimentos aqui relatados, ancorados em dados empíricos, podem ser sugestivos para a recolha de fontes autobiográficas, priorizando uma dimensão dialógica, mais horizontal entre participantes da pesquisa.

As escolhas, nos processos de transcrição, textualização e análises, alicerçaram-se na constatação de que as narrativas de crianças, nas rodas de conversa, são construídas por frases curtas, que se encadeiam no fio da conversa. Por essa razão, reunimos as micronarrativas em sequências mais longas, permitindo conceitualizar as narrativas coletivas com base em estudos que rompem com conceitos canônicos de modelos narrativos mais estruturais.

A opção por uma análise temática no processo de análise e escrita interpretativa foi guiada pelo cuidado de evitar a violência simbólica, enfatizando o respeito à palavra da criança de modo que ela possa ser acolhida com o respeito reservado à palavra do pesquisador. Tivemos igualmente o cuidado de proceder, ancorando os procedimentos metodológicos em estudos advindos de diferentes correntes das Ciências Humanas, que tomam a narrativa como uma ação inerentemente humana e, portanto, sugestiva dos processos de humanização do ponto de vista filogenético e ontogenético.

Este texto tem, portanto, como objetivo contribuir para o fortalecimento do debate sobre procedimentos de constituição de fontes autobiográficas e de suas análises na pesquisa qualitativa em Educação, enriquecendo, dentro do possível, as reflexões sobre a pesquisa com crianças, como sujeitos de sua história, de direitos e sujeitos sociohistóricos, suscetíveis de contribuírem com suas experiências e percepções para os avanços da educação e da pesquisa educacional.

\section{Notas}

Passeggi et al. (2014). Projeto "Narrativas da infância: o que contam as crianças sobre a esccola e os professores sobre a infância". CNPq-Brasil (Processo n. 462119/2014-9). Comitê de Ética n. 168.818.

Passeggi et al. (2016). Projeto "Pesquisa (auto)biográfica com criança: olhares da infância e sobre a infância". CNPq-Brasil (Processo n. 310582/2016-4). Comitê de Ética n. 168.818.

\section{Referências}

Barthes, R. (1966). Introduction à l'analyse structurale des récits. Communications, (8), pp. 1-27.

Bakhtin, M. (1995). Marxismo e filosofia da linguagem. São Paulo: Hucitec.

Bertaux, D. (2010). Narrativas de vida: a pesquisa e seus métodos. Natal: EDUFRN.

Bourdieu, P. (2003). Compreender. In A miséria do mundo (pp. 693-732). Petrópolis, RJ: Vozes.

Brockmeier, J., \& HARRÉ, R. (2003). Narrativa: problemas e promessas de um paradigma alternativo. Psicologia: Reflexão e Crítica, 18 (3), 525-535.

Bruner, J. (1997). Atos de significação. Porto Alegre: Artes Médicas. 
Delory-Momberger, Ch. (2012). Abordagens metodológicas na pesquisa biográfica. Revista Brasileira de Educação, 17 (51), 523-536.

Delory-Momberger, Ch. (2008). Biografia e educação. Figuras do indivíduo-projeto. Natal: EDUFRN.

Delory-Momberger, Ch. (2005). Histoire de vie et recherche biographique en éducation. Paris: Anthropos.

Jovchelovitch, S., \& Bauer, M. W. (2014). Entrevista narrativa. In: Bauer, M. W. \& Gaskell, G. Pesquisa qualitativa com texto, imagem e som: um manual prático (pp. 90-113). Petrópolis, RJ: Vozes.

Lani-Bayle, M., \& Passeggi, M.C. (Dir.). (2014). Raconter l'école: à l'écoute de vécus scolaires en Europe et au Brésil. Paris: L'Harmattan.

Passeggi, M. C. et al (2017). Narrativas autobiográficas com crianças na pesquisa qualitativa em educação: reflexão sobre procedimentos de análise. In: A. P. Costa, P. A. Castro, S. O Sá, \& R. A. Saavedra (Eds.), 60 Congresso Ibero-Americano em Investigação Qualitativa (CIAIQ2017) (pp.468477). Salamanca: Espanha.

Passeggi, M. C. (2014). Nada para a criança sem a criança: o reconhecimento de sua palavra para a pesquisa (auto)biográfica. In: Mignot, A., Sampaio, C. \& Passeggi, M. C. (Orgs.) Infância, aprendizagem e exercício da escrita (pp. 131-148). Curitiba: CRV.

Passeggi, M. C., et al (2014). Narrativas de crianças sobre as escolas da infância: cenários e desafios da pesquisa (auto) biográfica. Educação, 39 (1), 13-26.

Passeggi, M. C., Nascimento, G. L. S., \& Oliveira, R. C. A. M. (2016). As narrativas autobiográficas como fonte e método de pesquisa qualitativa em Educação. Revista Lusófona de Educação, 33 (33), 111-125.

Passeggi, M. C. (2016). O sujeito autobiográfico: noções terminológicas para a pesquisa (auto) biográfica com a criança. In: Passeggi, M. C., Furlanetto, E. C. \& Palma, R. (Orgs.) Pesquisa (auto) biográfica, infâncias, escola e diálogos intergeracionais (pp. 48-66). Curitiba: CRV.

Peloso, F. C. (2015). Infâncias do e no campo: um retrato dos estudos pedagógicos nacionais. Tese de doutoramento. São Carlos: Universidade Federal de São Carlos.

Poirier, J., Clapier-Valladon, S., \& Raybaut, P. (1996). Les récits de vie théorie et pratique. Paris: PUF.

Ricœur, P. (2010) Escritos e conferências 1. Em torno da psicanálise. São Paulo: Ed. Loyola.

Sarmento, M. J., \& Pinto, M. (2004). As culturas da infância nas encruzilhadas da $2^{\mathrm{a}}$ modernidade. In M. J. Sarmento, \& A. B. Cerisara. (Eds.), Crianças e miúdos: perspectivas sociopedagógicas da infância e educação. Porto: Edições Asa. 


\section{Maria da Conceição Passeggi}

Pesquisadora do CNPq - Pq2 Programa de Pós-Graduação em Educação Universidade Federal do Rio Grande do Norte (UFRN)

Universidade Cidade de São Paulo (UNICID)

E-mail: mariapasseggi@gmail.com

ORCID:0000-0002-4214-7700

Gilcilene Nascimento

Doutora em Educação

Universidade Federal Rural do Semi-Árido - UFERSA

E-mail: Ielianascimento@ufersa.edu.br

ORCID: 0000-0001-9295-2495

Senadaht Rodrigues

Doutoranda em Educação

Universidade Federal do Rio Grande do Norte - UFRN

E-mail: senadaht@yahoo.com.br

ORCID: 0000-0003-3888-4158

Correspondência

Maria da Conceição Passeggi

Rua Maranhão, 43, apt. 122, Ed. Arquitetura, Higienópolis

01240-001 São Paulo -SP| Brasil

Data de submissão: Março de 2017

Data de avaliação: Abril de 2017

Data de publicação: Julho 2018 